\title{
Diagnostic Accuracy of Consensus Diagnostic Criteria for Frontotemporal Dementia in a Memory Clinic Population
}

\author{
Yolande A.L. Pijnenburg ${ }^{a, b} \quad$ Jacqueline L. Mulder ${ }^{d} \quad$ John C. van Swieten ${ }^{e}$ \\ Bernard M.J. Uitdehaag ${ }^{b, c}$ Martijn Stevens ${ }^{f}$ Philip Scheltens $^{a, b}$ Cees Jonker ${ }^{a}$ \\ ${ }^{\mathrm{a}}$ Alzheimer Centre and Departments of ${ }^{\mathrm{b}}$ Neurology and ${ }^{\mathrm{C}} \mathrm{Clinical}$ Epidemiology and Biostatistics, \\ VU University Medical Centre, Amsterdam, ${ }^{\mathrm{d}}$ Department of Neuropsychology, Hagaziekenhuis, The Hague, \\ e Department of Neurology, Erasmus Medical Centre, Rotterdam, and ${ }^{\mathrm{f}}$ Department of Neurology, \\ Gooi Noord Hospital, Blaricum, The Netherlands
}

\section{Key Words}

Diagnostic accuracy • Frontotemporal dementia •

Consensus criteria, frontotemporal dementia

\begin{abstract}
Background/Aims: The goal of the present study was to evaluate the diagnostic accuracy of the core diagnostic criteria for frontotemporal dementia (FTD) [Neary D, et al: Neurology 1998;51:1546-1554] within a memory clinic population. Methods: The 5 core diagnostic criteria for FTD were operationalised in an informant-based written questionnaire. For a diagnosis of FTD the total clinical picture was weighted with findings on additional investigations and possible exclusion criteria, with follow-up of at least 1 year. Results: The operationalised core criteria for FTD had a sensitivity of $79 \%(95 \% \mathrm{Cl}=57-92)$ and a specificity of $90 \%(95 \%$ $\mathrm{Cl}=85-94)$. Conclusion: The core diagnostic criteria for FTD applied in a caregiver questionnaire have good diagnostic accuracy among subjects without advanced dementia attending a memory clinic. This stresses the importance of the informant-based history in the differential diagnosis of dementia.

Copyright ๑ 2008 S. Karger AG, Basel
\end{abstract}

\section{Introduction}

Frontotemporal dementia (FTD) is a neurodegenerative disorder predominantly affecting the frontal and temporal lobes, presenting with prominent behavioural and personality changes, followed by disturbances of executive functions, language and memory. Although often under-recognised, FTD accounts for about $13 \%$ of dementia cases and for $12-22 \%$ of dementia incidences starting before the age of 65 years [1,2]. In 1994 the Lund and Manchester international consensus meeting drew the attention towards the syndrome in a mainly descriptive way [3]. A few years later, the Lund and Manchester criteria were refined to the concept of frontotemporal lobar degeneration (FTLD), representing a clinical spectrum of the prototypical variants FTD, semantic dementia and progressive non-fluent aphasia [4]. For FTD a set of 5 core criteria was formulated together with a number of supportive features and exclusion criteria. In the most recent consensus conference, FTLD was simply divided into the behavioural and the language variants of FTD, whereas the main focus lies on pathological classification [5]. To date, the most broadly applied in clinical practice

\section{KARGER}

Fax +41613061234

E-Mail karger@karger.ch

www.karger.com (c) 2008 S. Karger AG, Basel

$1420-8008 / 08 / 0252-0157 \$ 24.50 / 0$

Accessible online at:

www.karger.com/dem
Yolande A.L. Pijnenburg, MD

Alzheimer Centre and Department of Neurology

VU University Medical Centre

PO Box 7057

NL-1007 MB Amsterdam (The Netherlands) 
are the Neary and Snowden diagnostic criteria [4]. In clinical practice, the use of these criteria raises several questions. Their reliability has only scarcely been investigated and no prospective studies have been performed. The most recent study investigated ante-mortem clinical diagnoses in 34 patients with autopsy-proven FTLD in a memory clinic cohort and found a sensitivity of $85 \%$ and a specificity of $99 \%$ of the Neary and Snowden diagnostic criteria [6]. In this study, diagnoses were based on the composite of the clinical syndrome, neuropsychological findings and neuroimaging results, evolving over time. A retrospective clinico-clinical study, however, found that the core clinical diagnostic criteria had a sensitivity of only $36.5 \%$ for FTD [7]. Moreover, it is hard to qualify and quantify behavioural and emotional characteristics represented in the 5 core diagnostic criteria, all needed for a diagnosis of FTD. As it is allowed to make a diagnosis of FTD based on purely clinical criteria, however, correct application of these behavioural criteria is essential. Observation of the patient is 1 means to do so, however, for a full appraisal of behavioural and emotional changes, the caregiver history is indispensable. In the current study the presence or absence of the Neary and Snowden core diagnostic criteria for FTD was rated by caregivers using an informant-based questionnaire. The diagnostic accuracy of the operationalised clinical diagnostic criteria was determined with reference to the multidisciplinary diagnosis confirmed by at least 1 year of followup.

\section{Methods}

\section{Development and Application of a Questionnaire}

A written caregiver questionnaire was developed in which the 5 core diagnostic criteria were formulated as a question. For example, 'an early change in personal behaviour' was formulated as: 'Has there been an evident change of his/her personal behaviour?' The addition 'early' is not formulated in this question, as only subjects with no or mild dementia were included (see patient section). On the other hand, to avoid a high number of positive answers in all cases with slight personal behaviour change, the addition 'evident' was made. Subsequently, only in case of a positive answer to the questions on 'behaviour towards other people' (question No. 2) and 'personal behaviour' (question No. 3) a second set of questions was presented to identify the type of behaviour or personality change. These were derived from various questionnaires and descriptions of characteristic behaviour in FTD in the literature $[3,8-12]$. The original Dutch version as well as a translation of the full questionnaire is illustrated in the appendix.

The questionnaire was sent to caregivers or relatives of subjects visiting the VU University Medical Centre (VUMC) memo- ry clinic prior to their first consultation, as part of the standard screening procedure. They were strictly instructed to fill in the questionnaire independently of the patient. The completed questionnaires were stored apart from the medical notes of the patients during the inclusion period. The subjects were referred for memory and/or behavioural complaints by general practitioners and medical specialists (neurologists, psychiatrists and geriatricians).

\section{Acquisition of Patients and Diagnostic Procedure}

All subjects underwent a standard diagnostic procedure including extensive and detailed medical and informant-based history, physical and neurological examination, screening laboratory tests, psychometric testing, EEG and MRI. Disease duration was calculated as the time difference between reported symptoms and time of presentation. Laboratory tests consisted of ESR, complete blood count, serum electrolytes, glucose, blood urea nitrogen/creatinine, liver enzymes, folate, vitamins B1, B6 and B12 and thyroid function. Psychometric testing included elements of the Wechsler Adult Intelligence Scale, 3rd Edition, Visual Association Test [13], 15 Word Recall, Digit Span, Trail Making Tests, Category Fluency, Stroop Colour Word Interference Test, elements of the Behavioural Assessment of the Dysexecutive Syndrome [14] and Rey-Osterrieth Complex Figure Test. Clinical Dementia Rating was assessed in all subjects [15]. In most cases the Mini-Mental State Examination (MMSE) was performed [16]. On indication, the patients underwent a second set of investigations, such as sleep registration. ${ }^{99 \mathrm{~m}} \mathrm{Tc}$-hexamethyl propyleneamine oxide (HMPAO) SPECT or ${ }^{18} \mathrm{~F}$-fluorodeoxyglucose PET were performed in case of suspected dementia but normal structural imaging or to differentiate between types of dementia, mostly FTD and Alzheimer's disease (AD). Diagnoses were made in a multidisciplinary team consisting of neurologists, a psychiatrist, a geriatrician, a clinical neurophysiologist, a radiologist and a neuropsychologist, who were blind to the questionnaire answers. Detailed history taking, cognitive examination and behavioural observation were part of the routine screening procedure. Diagnoses were based on the respective international diagnostic criteria [17-20]. The clinical diagnosis of FTD was based on personality and behavioural change resulting in social dysfunctioning, emotional blunting and lack of insight, taking into account the supportive and exclusion criteria of Neary and Snowden [4]. Stability of the multidisciplinary diagnosis of FTD after 1 year of clinical follow-up was used as the gold standard. All other diagnoses were kept under review and discussed in the multidisciplinary team after 1 year as well.

To increase the sample size, an additional 23 FTD patients who had undergone the same diagnostic procedure were recruited from memory clinics of the Hagaziekenhuis in The Hague (J. L.M.) and the Erasmus Medical Centre in Rotterdam (J.C.v.S.).

\section{Data Analysis}

In the period August 2002 to January 2005 from a total of 603 subjects 441 questionnaires were returned. One of the reasons for not returning the questionnaire was the lack of any reliable informant. Eighty-seven questionnaires were excluded for incorrect completion. These concerned questionnaires with $<5$ core questions filled in, or without specification of the behavioural and personal items in case of a positive answer to the screening questions. 
Table 1. Demographic and clinical characteristics of the main diagnostic groups

\begin{tabular}{|c|c|c|c|c|c|c|}
\hline Group & $\begin{array}{l}\text { FTD } \\
(n=19)\end{array}$ & $\begin{array}{l}\mathrm{AD} \\
(\mathrm{n}=70)\end{array}$ & $\begin{array}{l}\text { Other } \\
\text { dementias } \\
(\mathrm{n}=18)\end{array}$ & $\begin{array}{l}\text { MCI } \\
(n=30)\end{array}$ & $\begin{array}{l}\text { Subjective } \\
\text { complaints } \\
(\mathrm{n}=37)\end{array}$ & $\begin{array}{l}\text { Other } \\
\text { disorders } \\
(\mathrm{n}=19)\end{array}$ \\
\hline Sex (male:female) & $14: 5$ & $34: 36$ & $12: 6$ & $17: 13$ & $18: 19$ & $10: 9$ \\
\hline Age, years & $58(47-83)$ & $69(52-83)$ & $68(51-82)$ & $69(60-79)$ & $61(52-87)$ & $65(45-79)$ \\
\hline Disease duration, years & $5(2-8)$ & $3(1-10)$ & $2(1-10)$ & $3(0.5-6)$ & $3(1-10)$ & $3(1-5)$ \\
\hline Follow-up duration, months & $14(12-44)$ & $24(12-43)$ & $24(12-36)$ & $23(12-40)$ & $16(12-43)$ & $15(12-34)$ \\
\hline $\mathrm{CDR}$ & $1(0.5-1)$ & $1(0.5-1)$ & $1(0.5-1)$ & $0.5(0.5)$ & $0(0-0.5)$ & $0.5(0-1)$ \\
\hline MMSE & $27(19-30)$ & $23(7-29)$ & $23(15-28)$ & $28(21-30)$ & $29(25-30)$ & $28(19-30)$ \\
\hline
\end{tabular}

Values are displayed as medians (range). $\mathrm{MCI}=$ Mild cognitive impairment; disease duration = reported duration of symptoms till time of diagnosis; follow-up duration = duration of clinical follow-up since time of diagnosis; CDR = Clinical Dementia Rating.

Table 2. Sensitivity, specificity, positive and negative predictive values and positive and negative likelihood ratios calculated for the presence of 5 positive answers on the core item caregiver questionnaire $(\mathrm{n}=193)$

\begin{tabular}{lll}
\hline Measure & Point estimate & $95 \%$ CI \\
\hline Sensitivity, \% & 79 & $57-92$ \\
Specificity, \% & 90 & $85-94$ \\
PPV, \% & 47 & $31-64$ \\
NPV, \% & 98 & $94-99$ \\
LR+ & 8.1 & $4.9-13.4$ \\
LR- & 0.2 & $0.1-0.6$ \\
\hline
\end{tabular}

$\mathrm{PPV}=$ Positive predictive value $\mathrm{NPV}=$ negative predictive value; $\mathrm{LR}+=$ positive likelihood ratio; $\mathrm{LR}-=$ negative likelihood ratio.

Because the diagnosis of FTD is most relevant and most difficult in the early stages of dementia, subjects with moderate to advanced dementia (Clinical Dementia Rating $>1, \mathrm{n}=36$ ) were excluded from analysis. Moreover, subjects with an obvious explanation for cognitive decline at first presentation, other than neurodegenerative causes, were excluded. General examination revealed severe bradycardia with cerebral hypoperfusion $(\mathrm{n}=1)$, severe alcohol abuse $(n=2)$ and delirium $(n=2)$. MRI identified extensive vascular involvement or strategic infarcts $(n=16)$, posttraumatic abnormalities $(\mathrm{n}=3)$ and normal pressure hydrocephalus $(n=2)$. Temporal epilepsy was identified by EEG $(n=7)$. In all cases clinical follow-up confirmed that the clinical picture of cognitive deterioration could not otherwise be explained.

Eighty-eight patients were excluded because the clinical follow-up had been $<1$ year. Four patients had an initial diagnosis of FTD, AD or a psychiatric disorder that proved to be incorrect at follow-up. Because the follow-up of the second diagnosis was shorter than 1 year, these subjects were excluded as well.

Diagnostic Accuracy of FTD Consensus

Criteria
In the included cohort we calculated sensitivity, specificity, positive predictive value, negative predictive value and likelihood ratios for the presence of 5 positive criteria (positive test) as opposed to $<5$ positive criteria (negative test) including 95\% confidence intervals (CI). Where TN is true negative, TP is true positive, $\mathrm{FN}$ is false negative, and $\mathrm{FP}$ is false positive, specificity was defined as $\mathrm{TN} /(\mathrm{TN}+\mathrm{FP})$, sensitivity as $\mathrm{TP} /(\mathrm{TP}+\mathrm{FN})$, positive predictive value as $\mathrm{TP} /(\mathrm{TP}+\mathrm{FP})$ and negative predictive value as $\mathrm{TN} /(\mathrm{TN}+\mathrm{FN})$. The likelihood ratio for a positive test result was defined as sensitivity/(1 - specificity) and the likelihood ratio for a negative test result as $(1-$ sensitivity)/specificity. Using CIA software (version 2.1.1), 95\% CI were calculated.

After the addition of 23 FTD cases from other memory clinics the diagnostic odds ratio of the 5 core criteria was calculated as the ratio between TP $\times$ TN and FP $\times$ FN. Lastly, answers to the 20 behavioural and personality items were evaluated within the VUMC memory clinic population.

\section{Results}

A total of 193 subjects were included in the analysis. Demographic and clinical characteristics of the main diagnostic groups are displayed in table 1. Nineteen patients with a diagnosis of FTD were identified. Seventy patients had been diagnosed as having AD. Other dementias than FTD and AD included semantic dementia ( $\mathrm{n}=$ $5)$ and progressive non-fluent aphasia $(n=2)$, dementia with Lewy bodies $(n=6)$, corticobasal degeneration $(n=$ 3 ) and Parkinson's disease dementia $(n=2)$. Note that although the patients were at most mildly demented, MMSE scores in the lower range occurred in cases with severe language disturbances. Thirty-seven subjects had subjective complaints without cognitive impairment, and 30 subjects had mild cognitive impairment [19]. Other disorders included obstructive sleep apnoea syndrome in 1 patient and a self-limiting frontal lobe syndrome proba- 
Table 3. Clinical and demographic data of FTD patients

\begin{tabular}{|c|c|c|c|c|c|c|c|}
\hline Case & Sex & $\begin{array}{l}\text { Age } \\
\text { years }\end{array}$ & $\begin{array}{l}\text { Disease } \\
\text { duration } \\
\text { years }\end{array}$ & Presenting features & MMSE & $\begin{array}{l}\text { An- } \\
\text { swers }\end{array}$ & Remarks \\
\hline VUMC1 & $\mathrm{m}$ & 55 & 6 & hoarding, decreased self-care & 19 & 4 & \\
\hline VUMC2 & $\mathrm{f}$ & 64 & 3 & language disturbances & 28 & 4 & \\
\hline VUMC3 & $\mathrm{m}$ & 58 & 5 & disinhibition, emotional unconcern & 26 & 5 & \\
\hline VUMC4 & $\mathrm{m}$ & 57 & 6 & childish behaviour & $\mathrm{Np}$ & 5 & \\
\hline VUMC5 & $\mathrm{m}$ & 54 & 4 & prosopagnosia, restlessness & $\mathrm{Np}$ & 4 & \\
\hline VUMC6 & $\mathrm{m}$ & 56 & 4 & apathy, ritualistic behaviour & 27 & 5 & bipolar disorder in history \\
\hline VUMC7 & $\mathrm{m}$ & 83 & 5 & irritability, paranoid behaviour & 29 & 5 & \\
\hline VUMC8 & $\mathrm{m}$ & 52 & 2 & withdrawal, stereotyped behaviour & NP & 5 & \\
\hline VUMC9 & $\mathrm{m}$ & 47 & 5 & $\begin{array}{l}\text { language disturbances, decreased planning, } \\
\text { emotional lability }\end{array}$ & NP & 5 & \\
\hline VUMC10 & $\mathrm{f}$ & 58 & 8 & $\begin{array}{l}\text { language disturbances, socially inadequate } \\
\text { behaviour }\end{array}$ & 27 & 5 & \\
\hline VUMC11 & $\mathrm{f}$ & 65 & 3 & apathy, irritability & NP & 5 & \\
\hline VUMC12 & $\mathrm{m}$ & 57 & 5 & decrease of practical skills, self-centredness & 28 & 5 & \\
\hline VUMC13 & $\mathrm{m}$ & 73 & 2 & self-centredness, impulsiveness, aggression & 23 & 5 & \\
\hline VUMC14 & $\mathrm{m}$ & 54 & 5 & apathy, gluttony & 30 & 5 & \\
\hline VUMC15 & $\mathrm{f}$ & 63 & 3 & compulsiveness, emotional lability & 23 & 5 & \\
\hline VUMC16 & $\mathrm{m}$ & 53 & 4 & language disturbances & NP & 4 & \\
\hline VUMC17 & $\mathrm{m}$ & 67 & 3 & alcohol abuse, stereotyped behaviour & 25 & 5 & post-mortem: tau-, ubiquitin+ \\
\hline VUMC18 & $\mathrm{f}$ & 60 & 6 & loss of initiative, claiming behaviour & 24 & 5 & \\
\hline VUMC19 & $\mathrm{m}$ & 59 & 6 & obsessive-compulsive behaviour & 27 & 4 & \\
\hline $\mathrm{HZ1}$ & $\mathrm{m}$ & 55 & 8 & loss of initiative, stereotyped behaviour & 28 & 4 & \\
\hline $\mathrm{HZ2}$ & $\mathrm{m}$ & 70 & 5 & severe apathy & 29 & 5 & \\
\hline $\mathrm{HZ3}$ & $\mathrm{m}$ & 84 & 5 & aggression, claiming behaviour & NP & 5 & \\
\hline $\mathrm{HZ4}$ & $\mathrm{m}$ & 62 & 1 & emotional unconcern, apathy & NP & 4 & \\
\hline HZ5 & $\mathrm{m}$ & 54 & 2 & sexual disinhibition, stereotyped behaviour & 30 & 3 & $\begin{array}{l}\text { post-mortem: neuronal loss, } \\
\text { gliosis, tau-, ubiquitin-- }\end{array}$ \\
\hline HZ6 & $\mathrm{m}$ & 70 & 2 & withdrawal, irritability & 28 & 5 & \\
\hline HZ7 & $\mathrm{f}$ & 86 & 4 & emotional flattening, perseveration & 28 & 5 & \\
\hline HZ8 & $\mathrm{m}$ & 73 & 2 & emotional unconcern, apathy & 27 & 5 & \\
\hline HZ9 & $\mathrm{m}$ & 51 & 2 & emotional unconcern, socially inappropriate behaviour & 26 & 5 & \\
\hline HZ10 & $\mathrm{m}$ & 52 & 1 & disorganisation, aggression & 30 & 5 & \\
\hline HZ11 & $\mathrm{f}$ & 78 & 7 & aggression, disinhibition & NP & 5 & \\
\hline $\mathrm{HZ12}$ & $\mathrm{f}$ & 72 & 1 & language disturbances & 29 & 3 & \\
\hline EMC1 & $\mathrm{m}$ & 58 & 2 & concentration problems, language disturbances & NP & 4 & \\
\hline EMC2 & $\mathrm{m}$ & 72 & 5 & language disturbances & 30 & 4 & \\
\hline EMC3 & $\mathrm{f}$ & 52 & 3 & aggression, language disturbances & 13 & 5 & \\
\hline EMC4 & $\mathrm{m}$ & 52 & 3 & apathy, language disturbances & 20 & 5 & P301 MAPT mutation \\
\hline EMC5 & $\mathrm{m}$ & 51 & 4 & language disturbances, emotional unconcern & 29 & 5 & \\
\hline EMC6 & $\mathrm{f}$ & 66 & 6 & prosopagnosia, language disturbances & NP & 5 & \\
\hline EMC7 & $\mathrm{m}$ & 68 & 7 & socially inadequate behaviour, aggressive & 29 & 5 & \\
\hline EMC8 & $\mathrm{m}$ & 57 & 8 & disinhibition, language disturbances & $\mathrm{NP}$ & 5 & \\
\hline EMC9 & $\mathrm{m}$ & 78 & 5 & disinhibition, language disturbances & 19 & 4 & \\
\hline EMC10 & $\mathrm{m}$ & 40 & 10 & emotional unconcern, aggression & 23 & 4 & \\
\hline EMC11 & $\mathrm{m}$ & 72 & 4 & stereotyped behaviour, inhibition & 26 & 5 & \\
\hline
\end{tabular}

$\mathrm{NP}=$ Not performed; answers $=$ number of positive answers on caregiver questionnaire; MAPT $=$ microtubule-associated protein tau. 
bly related to cerebrovascular disease in another patient. Nine subjects mostly had symptoms of depression, anxiety or personality disorder. In 8 subjects the eventual diagnosis had been postponed. Post-mortem pathological confirmation was achieved in 1 patient with a clinical diagnosis of probable $\mathrm{AD}$ and in 1 patient with FTD.

In table 2 measures of diagnostic accuracy are displayed. The presence of 5 core diagnostic criteria according to the caregiver questionnaire had a sensitivity of $79 \%$ $(95 \% \mathrm{CI}=57-92)$ and a specificity of $90 \%(95 \% \mathrm{CI}=85$ 94) for a clinical diagnosis of FTD.

The 4 FTD patients who did not fulfil all 5 core criteria scored a total of 4 positive answers on the questionnaire. Thus, if a cut-off score of 4 positive core items had been applied, the sensitivity would have risen to $100 \%$, however, at the cost of the specificity, which would have dropped to $66 \%(95 \% \mathrm{CI}=59-73)$. A score $<5$ on the caregiver questionnaire had a negative predictive value of 98\% (95\% CI $=94-99)$, meaning that a diagnosis of FTD was almost excluded.

Seventeen subjects with other diagnoses than FTD had a score of 5 core diagnostic criteria. These included 8 out of 70 patients with probable $\mathrm{AD}, 3$ out of 6 patients with probable dementia with Lewy bodies, 3 individuals with subjective complaints and 2 persons in whom no definite diagnosis could be made. In 1 individual with subjective complaints and in 1 with a postponed diagnosis, a diagnosis of FTD was suspected.

Of the 19 subjects diagnosed as having FTD, 10 had abnormal structural imaging consistent with FTD, 6 had a frontal/temporal deficit on functional imaging $\left({ }^{18} \mathrm{~F}\right.$-fluorodeoxyglucose PET or HMPAO SPECT) and 17 had psychometric testing suggestive of FTD. In all cases at least 1 of these ancillary investigations was abnormal. In 1 patient the diagnosis of FTD was confirmed by postmortem neuropathological examination revealing spongiosis and gliosis of the temporal cortices, hippocampi and amygdalae with tau-negative, ubiquitin-positive inclusions.

The FTD sample was then enriched with 23 patients from 2 other memory clinics with questionable to mild dementia, all of whom had had follow-up of at least 1 year. Clinical and demographic data of the total group of FTD patients are presented in table 3 . The diagnostic odds ratio of the 5 core criteria was $23(95 \% \mathrm{CI}=10-53)$. The sensitivity of the 5 core criteria decreased to $71 \%$ (95\% $\mathrm{CI}=56-83)$.

Measures of diagnostic accuracy were calculated for the individual behavioural items for FTD (second page of the questionnaire). High specificities were found for im- pulsiveness (88\%), change of food preferences (82\%), change of hobbies (97\%) and self-centredness (83\%), however, with relatively low sensitivities $(41,35,16$ and $78 \%$ respectively). The items with the highest sensitivity were a reduction in spontaneous speech (less talkative, sensitivity $=94 \%)$, a change of emotional reactions $(94 \%)$ and reduced planning (100\%), all at low specificity (30, 39 and $12 \%$ respectively).

\section{Discussion}

This study examined the diagnostic accuracy of the core clinical diagnostic criteria for FTD operationalised in an informant-based questionnaire. The 5 core diagnostic features rated by caregivers had a good diagnostic accuracy to identify FTD among subjects presenting at a memory clinic who were at most mildly demented. The high diagnostic accuracy was maintained when combining data from our own patient cohort with those of 2 other memory clinics. Individual questions addressing different aspects of behaviour and personality were of less diagnostic value. Only a change of hobbies and interests yielded a specificity higher than the $90 \%$ specificity of the 5 core items. Moreover, impulsiveness, change of food preference and self-centredness were specific features for FTD (specificity $>80 \%$ ), at the cost of a relatively low sensitivity. Remarkably, some conducts that appear to be characteristic of FTD, such as stereotyped behaviour and perseveration, had a low specificity for FTD in our study $[21,22]$.

Although in our memory clinic population the core diagnostic criteria yielded a sensitivity of $79 \%$ and specificity of $90 \%$, we checked whether the good diagnostic accuracy was maintained by enriching our FTD sample. For this, we used the diagnostic odds ratio that is often used as a measure of the discriminative power of a test. A value of 1 means that the test discriminates at chance level. Very high values $>1$ mean that a test discriminates well. In our study the presence of 5 core items increases the odds of having FTD with a factor 23.

One of the strengths of this study is the prospective design with a relatively large number of subjects. Contrary to previous studies examining the diagnostic validity of clinical criteria by rating patient features using chart review $[6,7,23]$, the presence or absence of the core diagnostic criteria in our study was rated by the patients' caregivers. As behavioural and emotional changes that characterise the frontal lobe syndrome are highly environment dependent and might not directly come out in the structured setting of a memory clinic, caregivers who live 
with the patients can be considered the experts for assessing behavioural abnormality. The approach of a written questionnaire was chosen with the intention to obtain caregiver information at the highest possible reliability. The aim of the questionnaire, other than to collect behavioural information, was not disclosed to the caregivers. They were instructed to fill in the questionnaire independently of the patients. Moreover, their ratings were not influenced by the interpretation of the clinicians. Although we considered it an advantage for objectivity to use written questionnaires, it is remarkable that a relatively high number of subjects filled in the questionnaire incompletely or incorrectly. Because it was not our goal to develop a behavioural questionnaire, but to examine the presence or absence of the core diagnostic criteria of Neary and Snowden according to the caregiver by literally putting a question mark behind each criterion, we did not examine the face validity of the questions. It might be well possible that terms such as 'change of personal behaviour' were too abstract for caregivers or relatives.

Another strength is that we investigated a group of subjects with no, questionable or mild dementia, as clinical diagnosis is of most relevance in an early stage for prognostic and therapeutic reasons. The reproducibility of our findings was assessed by examining a proportion of subjects from 2 other memory clinics. Thus, our findings yield a relatively high diagnostic accuracy for FTD in an early to moderate stage, just by collecting written caregiver information. The sensitivity of the clinical diagnostic criteria in our cohort is higher than that found in a clinico-clinical study using chart review as a method to assess the presence or absence of the core criteria [7]. On the other hand, the fact that the clinical picture becomes clearer during the course of the disease might explain why sensitivities $>79 \%$ were found in 2 other studies $[6,23]$. To test this hypothesis, longer clinical followup of our cohort is needed, in particular of the 2 subjects with a positive questionnaire and a suspicion of FTD. In this respect, adding a degree of certainty to the existing diagnostic criteria, like it is applied in the criteria for other types of dementia $[17,18,20]$, would increase the awareness of cases with 'possible FTD' and encourage longterm clinical follow-up.

Although there are several explanations why our analysis could be performed in a relatively small proportion of the original number of 603 , it cannot be excluded that our results were biased by the fact that caregivers of subjects with the most pronounced behavioural changes were more likely to respond than those whose partners had no remarkable behaviours.
Our results can only be considered in the context of a memory clinic setting. Misdiagnosis of FTD in the early stages is common [24,25]. Because of the relatively young age of onset and the predominance of behavioural features, these patients are often referred for psychiatric evaluation [26]. FTD patients with the most prominent behaviour disturbances might therefore be referred to psychiatrists, whereas those with relatively more cognitive complaints are referred to a memory clinic. This selection bias could have particularly influenced the sensitivity of the diagnostic criteria in our study. On the other hand, it is conceivable that the specificity of the diagnostic criteria is much lower if the reference population consists of patients with psychiatric disorders.

We are aware that our study is hampered by inevitable circular evidence because the caregiver answers are not completely independent of the eventual clinical diagnosis. To escape full-circle reasoning, only the core criteria were evaluated using a written, informant-based questionnaire, prior to consultation. The additional personal and behavioural items served as a further specification as well as concrete examples. The clinical diagnosis of FTD, however, was based on clinician's judgements that weighed the contributions of a thorough behavioural and cognitive history and examination, supportive features including predominant frontal/temporal atrophy on MRI and executive dysfunction on neuropsychological examination, whereas subjects with features such as spatial disorientation were excluded. Moreover, the clinical diagnosis had to remain consistent over time, implicitly suggesting clinical progression. The results of this study therefore depend both on the reliability of the caregiver answers as well as clinical judgement.

Another weakness of our study is that pathological confirmation of the clinical diagnosis is lacking in the majority of cases. We excluded clear causes of cognitive disturbances, other than neurodegenerative dementia, because these could be identified at first evaluation and did not belong to the differential diagnosis of FTD. In the remaining subjects, long-term clinical follow-up was used as the gold standard and pathological confirmation was achieved in a small number of patients. As a tertiary referral centre using a multidisciplinary approach, we can rely on high diagnostic accuracy [27], but incorrect diagnosis in a proportion of patients cannot be fully excluded.

As the core clinical characteristics are central in the diagnostic criteria of FTD, the role of additional investigations remains to be investigated. The sensitivity of MRI has been reported to be between 50 and 64\% [6, 7]. Our 
findings seem to be in line with a relatively low sensitivity of structural neuroimaging for FTD, as only $53 \%$ had an abnormal MRI at presentation. The sensitivity of SPECT/PET scans is much higher, around 90\% [7]. Despite prominent behavioural change, however, both MRI, HMPAO SPECT and psychometric testing may be normal in the early stages of FTD [28]. Thus, behavioural changes may precede abnormal investigations. This could be another argument to add a degree of certainty ('possible', 'probable', 'definite') to the existing clinical diagnostic criteria. The diagnostic accuracy of the criteria is expected to be lower in less selected and less specialised settings. Therefore, a need for biomarkers capable of identifying FTD remains. Ideally these could serve as an aid to predict pathological phenotypes as well [29].

In conclusion the core diagnostic criteria of Neary and Snowden, applied in an informant-based questionnaire, appear to be an appropriate tool for the early diagnosis of FTD in a memory clinic. These findings stress that caregiver information plays an important role in the diagnosis of FTD. The challenge remains to evaluate the diagnostic accuracy for FTD within a psychiatric setting.

\section{Appendix}

\section{Core Questionnaire and Additional Questions}

The subjects were asked to have the questionnaire filled in by a person who knew them well, for example their spouse, a relative or a good friend. The relatives or caregivers were instructed to fill in the questionnaire according to their personal view. It was requested to note the relationship of the rater towards the rated individual.

1 Has there been a gradual onset and gradual progression? Yes No

2 Has there been an evident change in his/her behaviour towards other people?

If yes, please answer the questions on the next page.

3 Has there been an evident change in his/her personal behaviour?

If yes, please answer the questions on the next page.

4 Does he/she show lack of emotional concern?

5 Are complaints about his/her condition absent or does he/she deny these?

$\begin{array}{cc}\text { Yes } & \text { No } \\ \text { Yes } & \text { No } \\ & \\ \text { Yes } & \text { No } \\ & \\ \text { Yes } & \text { No } \\ \text { Yes } & \text { No } \\ & \end{array}$

\section{If you answered yes to question number 2,}

please answer the following questions.

1 Does he/she make inappropriate remarks or jokes?

2 Has he/she become argumentative?

3 Has he/she become socially withdrawn?

4 Has he/she become less talkative?

5 Other:

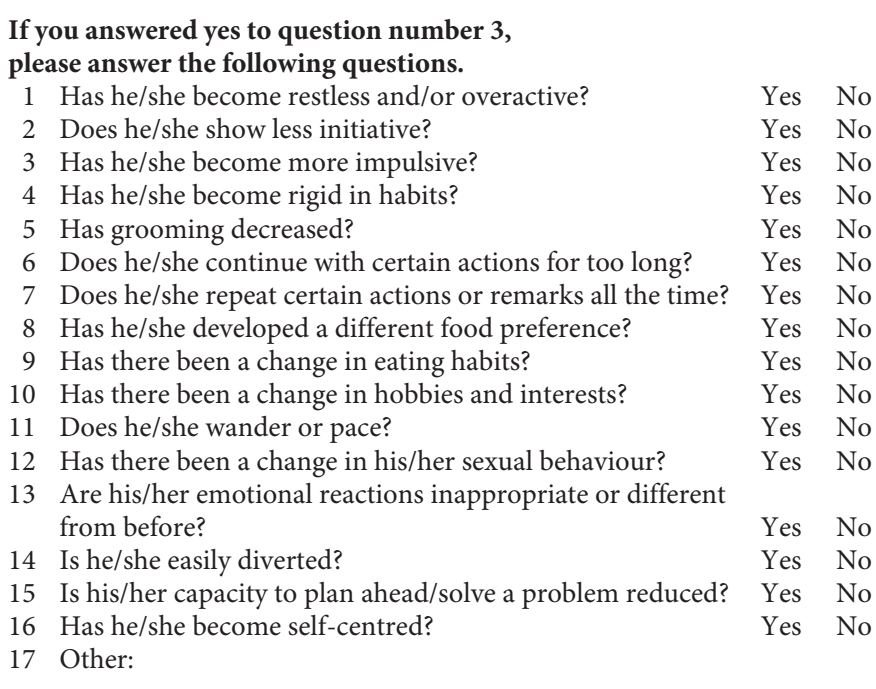

lease answer the following questions.

1 Has he/she become restless and/or overactive? Yes No

2 Does he/she show less initiative? Yes No

3 Has he/she become more impulsive? $\quad$ Yes No

4 Has he/she become rigid in habits? Yes No

5 Has grooming decreased? $\quad$ Yes No

6 Does he/she continue with certain actions for too long? Yes No

7 Does he/she repeat certain actions or remarks all the time? Yes No

8 Has he/she developed a different food preference? Yes No

9 Has there been a change in eating habits? Yes No

10 Has there been a change in hobbies and interests? Yes No

11 Does he/she wander or pace? Yes No

12 Has there been a change in his/her sexual behaviour? Yes No

13 Are his/her emotional reactions inappropriate or different rom before? Yes No

Is he/she easily diverted? $\quad$ Yes No

15 Is his/her capacity to plan ahead/solve a problem reduced? Yes No

17 Other:

Yes $\mathrm{No}$

Yes No

\section{References}

1 Ikeda M, Ishikada T, Tanabe H: Epidemiology of frontotemporal lobar degeneration. Dement Geriatr Cogn Disord 2004;17:265268.

$\checkmark 2$ Ratnavalli E, Brayne C, Dawson K, Hodges JR: The prevalence of frontotemporal dementia. Neurology 2002;58:1615-1621.

-3 The Lund and Manchester Groups: Clinical and neuropathological criteria for frontotemporal dementia. J Neurol Neurosurg Psychiatry 1994;57:416-418.

Diagnostic Accuracy of FTD Consensus Criteria
4 Neary D, Snowden JS, Gustafson L, Passant U, Stuss D, Black S, Freedman M, Kertesz A, Robert PH, Albert M, Boone K, Miller BL, Cummings J, Benson DF: Frontotemporal lobar degeneration: a consensus on clinical diagnostic criteria. Neurology 1998;51: 1546-1554.

5 McKhann GM, Albert MS, Grossman M, Miller B, Dickson D, Trojanowski JQ: Clinical and pathological diagnosis of frontotemporal dementia: report of the Work Group on Frontotemporal Dementia and Pick's Disease. Arch Neurol 2001;58:1803-1809.
6 Knopman DS, Boeve BF, Parisi JE, Dickson DW, Smith GE, Ivnik RJ, Josephs KA, Petersen RC: Antemortem diagnosis of frontotemporal lobar degeneration. Ann Neurol 2005;57:480-488.

7 Mendez MF, Shapira JS, McMurtray A, Licht E, Miller BL: Accuracy of the clinical evaluation for frontotemporal dementia. Arch Neurol 2007;64:830-835.

8 Gustafson L: Frontal lobe degeneration of non-Alzheimer type. II. Clinical picture and differential diagnosis. Arch Gerontol Geriatr 1987;6:209-223. 
9 Barber R, Snowden JS, Craufurd D: Frontotemporal dementia and Alzheimer's disease: retrospective differentiation using information from informants J Neurol Neurosurg Psychiatry 1995;59:61-70.

-10 Bozeat S, Gregory CA, Lambon Ralph MA, Hodges JR: Which neuropsychiatric and behavioural features distinguish frontal and temporal variants of frontotemporal dementia from Alzheimer's disease? J Neurol Neurosurg Psychiatry 2000;69:178-186.

11 Snowden JS, Bathgate D, Varma A, Blackshaw A, Gibbons ZC, Neary D: Distinct behavioural profiles in frontotemporal dementia and semantic dementia. 2001;70:323332.

$\checkmark 12$ Ikeda M, Brown J, Holland AJ, Fukuhara R, Hodges JR: Changes in appetite, food preference, and eating habits in frontotemporal dementia and Alzheimer's disease. J Neurol Neurosurg Psychiatry 2002;73:371-376.

13 Lindeboom J, Schmand B, Tulner L, Walstra G, Jonker C: Visual association test to detect early dementia of the Alzheimer type. J Neurol Neurosurg Psychiatry 2002;73:126-133.

14 Krabbendam L, de Vugt ME, Derix MM, Jolles J: The behavioural assessment of the dysexecutive syndrome as a tool to assess executive functions in schizophrenia. Clin Neuropsychol 1999;13:370-375.

$\checkmark 15$ Morris JC: The Clinical Dementia Rating (CDR): current version and scoring rules. Neurology 1993;43:2412-2414.

-16 Folstein MF, Folstein SE, McHugh PR: 'Minimental state': a practical method for grading the cognitive state of patients for the clinician. J Psychiatr Res 1975;12:189-198.
17 McKeith IG, Galasko D, Kosaka K, Perry EK, Dickson DW, Hansen LA, Salmon DP, Lowe J, Mirra SS, Byrne EJ, Lennox G, Quinn NP, Edwardson JA, Ince PG, Bergeron C, Burns A, Miller BL, Lovestone S, Collerton D, Jansen EN, Ballard C, de Vos RA, Wilcock GK, Jellinger KA, Perry RH: Consensus guidelines for the clinical and pathologic diagnosis of dementia with Lewy bodies (DLB): report of the consortium on DLB international workshop. Neurology 1996;47:1113-1124.

18 McKhann G, Drachman D, Folstein M, Katzman R, Price D, Stadlan EM: Clinical diagnosis of Alzheimer's disease: report of the NINCDS-ADRDA Work Group under the auspices of Department of Health and Human Services Task Force on Alzheimer's Disease. Neurology 1984;34:939-944.

19 Petersen RC, Smith GE, Waring SC, Ivnik RJ, Tangalos EG, Kokmen E: Mild cognitive impairment: clinical characterization and outcome. Arch Neurol 1999;56:303-308.

20 Roman GC, Tatemichi TK, Erkinjuntti T, Cummings JL, Masdeu JC, Garcia JH, Amaducci L, Orgogozo JM, Brun A, Hofman A: Vascular dementia: diagnostic criteria for research studies - Report of the NINDSAIREN International Workshop. Neurology 1993;43:250-260.

21 Snowden JS, Neary D, Mann DM: Frontotemporal dementia. Br J Psychiatry 2002; 180:140-143.

22 Miller BL, Ikonte C, Ponton M, Levy M, Boone K, Darby A, Berman N, Mena I, Cummings JL: A study of the Lund-Manchester research criteria for frontotemporal dementia: clinical and single-photon emission CT correlations. Neurology 1997;48:937-942.
Rosen HJ, Hartikainen KM, Jagust W, Kramer JH, Reed BR, Cummings JL, Boone K, Ellis W, Miller C, Miller BL: Utility of clinical criteria in differentiating frontotemporal lobar degeneration (FTLD) from AD. Neurology 2002;58:1608-1615.

24 Pasquier F, Lebert F, Lavenu I, Guillaume B: The clinical picture of frontotemporal dementia: diagnosis and follow-up. Dement Geriatr Cogn Disord 1999;10(suppl 1):1014.

25 Mendez MF, Selwood A, Mastri AR, Frey WH: Pick's disease versus Alzheimer's disease: a comparison of clinical characteristics. Neurology 1993;43:289-292.

-26 Passant U, Elfgren CE, Englund E, Gustafson L: Psychiatric symptoms and their psychosocial consequences in frontotemporal dementia. Alzheimer Dis Assoc Disord 2005;19: S15-S18.

27 Mok W, Chow TW, Zheng L, Mack WJ, Miller C: Clinicopathological concordance of dementia diagnoses by community versus tertiary care clinicians. Am J Alzheimers Dis Other Demen 2004;19:161-165.

28 Gregory CA, Serra-Mestres J, Hodges JR: Early diagnosis of the frontal variant of frontotemporal dementia: how sensitive are standard neuroimaging and neuropsychologic tests? Neuropsychiatry Neuropsychol Behav Neurol 1999;12:128-135.

-29 Forman MS, Farmer J, Johnson JK, Clark CM, Arnold SE, Coslett HB, Chatterjee A, Hurtig HI, Karlawish JH, Rosen HJ, Van Deerlin V, Lee VMY, Miller BL, Trojanowski LQ, Grossman M: Frontotemporal dementia: clinicopathological correlations. Ann Neurol 2006;59:952-962. 